\title{
Original Article (short paper) \\ Association between different contexts of physical activity and abdominal obesity and excess weight in adolescents.
}

\author{
Priscila Custódio Martins ${ }^{1}$, Tiago Rodrigues de Lima ${ }^{1}$, Diego Augusto Santos Silva ${ }^{1 *}$ \\ ${ }^{1}$ Universidade Federal de Santa Catarina, UFSC, Florianópolis, SC, Brazil.
}

\begin{abstract}
Aim: To investigate the association between different contexts of physical activity (school commuting, participation in Physical Education classes, school recess, physical activity to improve muscular strength / endurance and overall physical activity) with abdominal obesity and excess weight in adolescents. Method: Cross-sectional study with 1,132 adolescents (14-19 years), enrolled in public schools in São José, Brazil. Information regarding the contexts of physical activity was obtained through questionnaires. The anthropometric indicators used to identify excess weight and abdominal obesity were body mass index (BMI) and waist circumference (WC). Binary logistic regression was used to estimate the odds ratio (OR) and 95\% confidence interval $(95 \% \mathrm{CI})$. Results: Adolescents who actively commuted to school for 10 minutes or longer were $36 \%$ less likely (OR: $0.64,95 \%$ CI: 0.58 a 0.71 ) of having abdominal obesity investigated by WC and 25\% less likely (OR: $0.75,95 \%$ CI: 0.65 a 0.86 ) of having excess weight investigated by means of BMI. The other physical activity contexts were not associated with anthropometric indicators. Conclusion: Active commuting to school was associated with lower odds of having abdominal obesity and excess weight in adolescents. Thus, active commuting to school can be an alternative for maintaining adequate levels of body composition.
\end{abstract}

Keywords: students, obesity, adolescent health, overweight, physical activity.

\section{Introduction}

Anthropometric indicators are used to investigate body composition and diagnose health risks, such as overweight and body fat accumulation ${ }^{1}$. This context, waist circumference (WC) and body mass index (BMI) are instruments that are easy to apply and have good accuracy ${ }^{2}$, and are used to define body fat distribution in the abdominal region and excess weight, respectively ${ }^{3}$.

Fat accumulation in the abdominal region is considered an important discriminator of excess weight ${ }^{3}$. Abdominal fat secretes higher concentrations of adipokines linked to inflammatory processes in relation to fat located in other regions of the body and is associated with arterial hypertension and metabolic syndrome ${ }^{1}$. Excess weight (overweight and obesity) when investigated by BMI in adolescents, is directly associated with health problems in adulthood, such as dyslipidemias and cardiovascular diseases (heart failure and heart attack) ${ }^{1}$.

Among the strategies for coping with abdominal obesity and excess weight in adolescents, increased levels of physical activity are often investigated ${ }^{4}$, since the performance of physical activity contributes to negative energy balance, favoring the control of fat accumulation in the abdominal region and excess weight ${ }^{5}$. The practice of physical activity can be carried out in several contexts such as school, physical education classes, during school recess or in activities whose objective is to improve muscular strength and endurance ${ }^{4}$. Such contexts are directly associated with higher levels of regular physical activity, and this increase promotes physiological and biopsychosocial changes and health benefits $^{6,7}$. However, the relationship between performance of physical activity in various contexts with abdominal fat and excess weight is not fully understood ${ }^{7,8}$. Thus, it is important to know which of these contexts are most strongly associated with high body fat.

Investigating physical activity in school is important, as this context is susceptible to intervention. In addition, exploring the different contexts within the school environment can bring significant contributions to the planning of actions and interventions, as adolescents spend much of their time in school, and Physical Education classes and school recess may be privileged spaces to promote the practice of physical activities ${ }^{9}$. Another important context for adolescents is how much physical activity they perform to improve muscle strength / endurance, since adequate levels of these components are predictors of adequate health ${ }^{10}$. In addition, investigating global physical activity is justified, since failure to comply with physical activity recommendations is considered an independent factor for increased abdominal fat and excess body weight ${ }^{11}$.

Several studies have been developed seeking to understand the relationship between physical activity and body fat (investigated through BMI or WC $)^{2,6,7}$. However, this work differs from the others because it investigated different contexts of physical activity in the same sample. This information can be useful for health professionals and Physical Education teachers who can intervene in different ways in the school population.

The aim of this study was to investigate the association between different contexts of physical activity (commuting to school, participation in Physical Education classes, school recess, 
physical activity to improve muscular strength / endurance and overall physical activity) with abdominal obesity and excess weight. The main hypothesis of the present study was that higher levels of physical activity in different contexts were associated with better results in relation to the indicators of overweight and body fat (body mass index and waist circumference) in adolescents.

\section{Method}

This cross-sectional, school-based, epidemiological survey was carried out in 2014 in the city of São José / Santa Catarina, Brazil. The study sample consisted of 5,182 students aged 1419 years enrolled in public high schools in the city of São José, distributed into 11 eligible schools and 170 high school classes. The sample process was determined in two stages: 1) stratified by state public high schools $(\mathrm{n}=11) ; 2$ ) class clusters considering study shift and school grade ( $\mathrm{n}=170$ classes). In stage two, all high school students who were present in classroom on the days of data collection were invited to participate in the study. The probabilistic sample consisted of 1,132 adolescents. Details on the estimates for sample size calculation and the entire sampling process (inclusion, exclusion criteria, eligibility) can be found in literature ${ }^{12}$.

The study was approved by the Ethics Committee for Research with Human Beings of the Federal University of Santa Catarina under protocol No. 746.536 of 2014. Only subjects who returned the informed consent form signed by parents $(<18$ years) or themselves ( $\geq 18$ years), along with the consent form signed by participants participated in this study.

\section{Dependent Variables}

WC was measured in the narrower portion of the trunk, between the lower costal border and the iliac crest, with Sanny ${ }^{\circledR}$ anthropometric tape (São Paulo, Brazil) ${ }^{13}$. To classify adolescents with abdominal obesity, the cutoff points proposed by Taylor and colleagues ${ }^{13}$ were used, which defined values with $\mathrm{Z}$ score $\geq 1$ as excess abdominal obesity. These cutoff points approach the $85^{\text {th }}$ percentile, considering the cutoff point for overweight through $\mathrm{BMI}^{14}$. These cutoff points were proposed according to age and sex (sensitivity and specificity values for females of $84 \%$ and $94 \%$ and for males and of $87 \%$ and $92 \%$, respectively $)^{13}$.

BMI uses body mass and height to identify the individual's body mass status. Height was collected through Sanny ${ }^{\circledR}$ stadiometer with tripod (São Paulo, Brazil) and body weight by G-tech ${ }^{\circledR}$ digital scale (Zhongshan, China). In order to classify the results in relation to BMI, cutoff points in Z-scores proposed by the World Health Organization were used ${ }^{14}$, in which the definition of overweight is $>+1$ standard deviation and obesity is $>+2$ standard deviations. In the present study, schoolchildren classified above $>+1$ standard deviation were considered overweight and those below this classification as normal weight ${ }^{14}$. The estimation of the technical error of measurement (TEM) was made in 20 adolescents. The intra-evaluative TEM for skinfolds was $3.5 \%$ and, for measures of perimeter and height, $1 \%$. The inter-assaying TEM was $7 \%$ for skinfolds and $1 \%$ for the other measures. Thus, the anthropometrists were at adequate levels to evaluate the anthropometric measures.

\section{Independent variables}

Variables related to commuting to school and Physical Education classes are included in the questionnaire Behavior of Adolescents from Santa Catarina (COMPAC), whose r values for the independent items, grouped by thematic unit, ranged from 0.64 to $0.99^{15}$.

Commuting to school was verified by the following questions: "How do you usually go to school?" And "How much time do you spend on this commuting?", and the answers to such questions were classified as passive (car, motorbike and bus) and active but less than 10 minutes (on foot or bicycle) and 10 minutes or more (on foot and bicycle). The number of Physical Education classes was collected by the question "During a typical week, how many Physical Education classes do you participate in?" The answers to this item were classified into no classes per week; one class per week; two classes per week; and three or more classes per week.

The questions regarding the performance of physical activity during school recess were given through the Physical Activity Questionnaire for Older Children (PAQ-C), validated by Kowalski, Crocker, \& Faulkner ${ }^{16}$ and translated into Portuguese by Guedes and Guedes ${ }^{17}$. This questionnaire had a good intraclass correlation coefficient of 0.75 and 0.82 for boys and girls, respectively. Physical activity during school recess was investigated by the question "In the last 7 days, what did you do for most of the recess or break?", in which responses were dichotomized into sedentary behavior (sitting) and physical activity (walking, running, actively playing).

Variables related to the performance of physical activity to improve endurance and muscular strength is included in the "Saúde na Boa" questionnaire, validated for Brazilian adolescents with intraclass correlation coefficient values ranging from 0.76 to $0.93^{18}$ through the following question: "During a typical week, how many days do you exercises to improve tone and strength of your muscles, such as bodybuilding and gymnastics?" and responses to this question were classified as non-performing, 1 to 2 days per week, 3 to 4 days per week and 5 or more days per week. Global physical activity variable was evaluated by the Brazilian version of the Youth Risk Behavior Surveillance (YRBSS), used in the United States, translated and validated for Brazil, with a moderately high agreement index with a vmean of $68.3 \%$ and a median of $68.5 \%{ }^{19}$.

Global physical activity was investigated by the question: "During the past seven days, on how many days have you been physically active for at least 60 minutes a day?" The answer options for this question ranged from one to seven days a week. From the option chosen by participants, the number of times in the week was multiplied by 60 (minutes), which allowed verifying how many minutes per week the participant performed physical activity. The results of this questioning were classified 
in less than 300 minutes per week, 300 minutes per week and more than 300 minutes per week.

\section{Control Variables}

"The sociodemographic variables were: gender (male / female) and age (full years) and categorized into 14/15, 16/17 and 18/19 years of age. Family income was collected according to the Brazilian Institute of Geography and Statistics ${ }^{20}$ in the number of minimum wages received between family members (minimum wage equivalent to $\mathrm{R} \$ 724.00$ in the data collection period - US $\$ 1.0=\mathrm{R} \$ 2.65$ ) and categorized: two minimum wages ); Two to ten minimum wages (intermediaries); Above ten minimum wages (high). Education level of the mother was collected in complete years and classified in $<$ eith years of study and eight years or more of study ${ }^{20 .}$

Sexual maturation was self-rated by adolescents using maturational development boards proposed by Marshall and Tanner ${ }^{21}$, elaborated by the Department of Nutrition of the Federal University of Santa Catarina, in which the result of the Kendall correlation coefficient was 0.627 ( $p<0.01)$ for boys and $0.739(\mathrm{p}<0.01)$ for girls ${ }^{22}$. In the present study, few adolescents were in the pre-pubertal maturation stage $(2.2 \%)$, and were excluded from the analysis. For the classification of this variable, adolescents were classified into pubertal and post-pubertal maturational stage, in which adolescents in stages 2 and 3 were classified as pubertal and those in stages 4 and 5 as post-pubertal.

\section{Statistical analysis}

For the analysis of the association of adolescents' characteristics with abdominal obesity and excess body fat with other variables, the chi-square tests with Rao-Scott correction and Fischer's exact test were used. Subsequently, these associations were evaluated in the context of binary logistic regression models, with an odds ratio estimation and $95 \%$ confidence intervals (CI 95\%). Interactions between all independent variables were tested, considering a value $\mathrm{p}<0.10$, but no interactions were identified. All analyses were corrected by the design effect and for sampling plan of the study the svy command from the Stata software (Statistical Software for Professionals, Texas, United States), version 13.0 was used. In the adjusted analyses, (both to investigate the relationship between abdominal obesity and excess body fat with the other variables), all variables were inserted (including WC for the BMI model and vice versa) at the same level, regardless of $\mathrm{p}$ value in the crude analysis, and only those with $\mathrm{p}$ value $\leq 0.20$ remained in the model, according to the backward method.

Sex, age, monthly family income, maternal schooling and sexual maturation were used as control variables throughout the model, regardless of $p$ value. In order to evaluate the final models (variables associated with abdominal obesity and excess body fat), two saturated models were estimated with all possible interactions among independent variables included in each model, in addition to models with logistic regression intercept values, so that the adjustment parameters could be compared to each other. In these comparisons, pseudo $\mathrm{R}^{2}$, Likelihood Ratio, Akaike Information Criterion (AIC) and Bayesian Information Criterion (BIC) were estimated. The significance of variables inserted in the models was verified through the Wald test in which value of $\mathrm{p}<0.05$ indicates association.

\section{Results}

Of the 1,132 students analyzed, 932 had information regarding $\mathrm{WC}$ and 1,008 had data regarding BMI. The sample distribution according to the investigated variables is shown in Table 1.

The prevalence of students with abdominal obesity and excess body weight was $11.0 \%$ and $26.2 \%$, respectively. For abdominal obesity, no significant difference in relation to the variables investigated was observed. Overweight was associated with pubertal adolescents and those who performed less than 300 minutes of physical activity per week were associated with excess body fat $(\mathrm{p}<0.05)$ (Table 1$)$.

Table 1. Total sample distribution according to abdominal obesity and excess weight of schoolchildren enrolled in public schools of São José, SC, Brazil, 2014.

\begin{tabular}{|c|c|c|c|c|c|c|c|}
\hline \multicolumn{8}{|c|}{ Variables } \\
\hline & \multirow{2}{*}{$\begin{array}{c}\text { Sample } \\
\text { n (\%) }\end{array}$} & \multicolumn{3}{|c|}{ Abdominal Obesity } & \multicolumn{3}{|c|}{ Excess weight } \\
\hline & & $\mathbf{n}$ & $\%(95 \%$ CI $)$ & p value & $\mathbf{n}$ & $\%(95 \%$ CI $)$ & p value \\
\hline Total & $1.132(100 \%)$ & 103 & $11.0(8.7-13.7)$ & & 266 & $26.2(22.9-29.9)$ & \\
\hline \multicolumn{8}{|l|}{ Sex } \\
\hline Male & $519(45.8)$ & 49 & $46.7(28.6-65.6)$ & $0.97^{*}$ & 119 & $45.1(21.5-71.2)$ & $0.40 *$ \\
\hline Female & $613(54.2)$ & 54 & $53.3(34.4-71.3)$ & & 147 & $54.9(28.8-78.5)$ & \\
\hline \multicolumn{8}{|c|}{ Age (years) } \\
\hline 14-15 & $361(31.8)$ & 21 & $26.6(17.7-37.8)$ & $0.53^{*}$ & 89 & $33.3(28.5-38.6)$ & $0.06^{*}$ \\
\hline $16-17$ & $649(57.4)$ & 61 & $58.7(52.0-65.1)$ & & 155 & $58.2(53.4-62.9)$ & \\
\hline $18-19$ & $122(10.8)$ & 15 & $14.7(7.0-28.4)$ & & 22 & $8.5(6.5-10.8)$ & \\
\hline
\end{tabular}




\begin{tabular}{|c|c|c|c|c|c|c|c|}
\hline \multirow[t]{3}{*}{ Variables } & \multirow{3}{*}{$\begin{array}{c}\text { Sample } \\
\text { n (\%) }\end{array}$} & \multirow{2}{*}{\multicolumn{3}{|c|}{ Abdominal Obesity }} & \multirow{2}{*}{\multicolumn{3}{|c|}{ Excess weight }} \\
\hline & & & & & & & \\
\hline & & $\mathbf{n}$ & $\%(95 \% \mathrm{CI})$ & p value & n & $\%(95 \% \mathrm{CI})$ & p value \\
\hline \multicolumn{8}{|l|}{ Monthly family income (minimum wage) ${ }^{\mathrm{a}}$} \\
\hline Up to two MW & $253(26.9)$ & 23 & $27.2(19.3-36.9)$ & $0.99 * *$ & 61 & $26.6(19.9-34.7)$ & $0.93 *$ \\
\hline Two to ten MW & $639(68.3)$ & 58 & $68.0(43.5-85.4)$ & & 157 & $68.0(58.4-76.2)$ & \\
\hline Above ten MW & $44(4.8)$ & 04 & $4.8(2.9-17.8)$ & & 12 & $5.4(3.4-8.3)$ & \\
\hline \multicolumn{8}{|l|}{ Maternal Schooling } \\
\hline $0-8$ years & $631(56.2)$ & 50 & $49.6(25.6-73.8)$ & $0.27 *$ & 120 & $46.1(25.6-68.0)$ & $0.48 *$ \\
\hline $9-11$ years & $487(43.8)$ & 53 & $50.4(26.2-74.4)$ & & 144 & $53.9(32.0-74.4)$ & \\
\hline \multicolumn{8}{|l|}{ Sexual maturation } \\
\hline Pubertal & $613(65.8)$ & 53 & $58.1(41.0-73.5)$ & $0.15^{*}$ & 130 & $55.4(52.5-58.4)$ & $<0.01^{\mathrm{b} *}$ \\
\hline Post-pubertal & $320(34.2)$ & 37 & $41.9(26.5-59.0)$ & & 104 & $44.6(41.6-47.5)$ & \\
\hline \multicolumn{8}{|l|}{ Commuting to school } \\
\hline Passive & $583(53.6)$ & 57 & $57.4(11.0-93.6)$ & $0.33^{*}$ & 140 & $54.9(9.5-93.4)$ & $0.41 *$ \\
\hline$<10$ minutes & $189(16.5)$ & 19 & $17.4(2.9-59.6)$ & & 48 & $17.6(3.3-56.7)$ & \\
\hline 10 minutes or more & $329(29.8)$ & 25 & $25.2(4.8-68.8)$ & & 72 & $27.5(6.0-68.9)$ & \\
\hline \multicolumn{8}{|l|}{ Number of Physical Education classes } \\
\hline No class per week & $74(6.8)$ & 11 & $11.1(3.0-33.8)$ & $0.18 * *$ & 19 & $7.5(2.0-23.6)$ & $0.94 *$ \\
\hline One class per week & $201(18.3)$ & 14 & $13.4(8.0-21.6)$ & & 38 & $14.5(8.8-22.9)$ & \\
\hline Two classes per week & $747(66.4)$ & 74 & $71.4(45.4-88.2)$ & & 187 & $70.9(54.4-83.3)$ & \\
\hline Three or more classes per week & $95(8.5)$ & 04 & $4.1(1.8-8.9)$ & & 18 & $7.1(4.1-12.0)$ & \\
\hline \multicolumn{8}{|l|}{ Physical activity during school recess } \\
\hline Sedentary behavior (sitting) & $640(57.3)$ & 66 & $64.8(61.1-68.2)$ & $0.10^{*}$ & 151 & $57.0(39.6-72.8)$ & $0.86^{*}$ \\
\hline $\begin{array}{l}\text { Physical activity (walking, running, actively } \\
\text { playing) }\end{array}$ & $475(42.7)$ & 36 & $35.2(31.8-38.9)$ & & 112 & $43.0(27.1-60.4)$ & \\
\hline \multicolumn{8}{|l|}{$\begin{array}{l}\text { Physical activity to improve endurance and } \\
\text { muscle strength }\end{array}$} \\
\hline Does not perform & $637(57.3)$ & 60 & $58.6(46.1-70.0)$ & $0.50 *$ & 143 & $53.8(39.4-67.6)$ & $0.27 *$ \\
\hline 1 to 2 days/week & $202(18.0)$ & 18 & $17.6(15.7-19.7)$ & & 43 & $16.4(9.8-26.0)$ & \\
\hline 3 to 4 days/week & $119(10.6)$ & 13 & $13.2(7.6-22.1)$ & & 35 & $13.5(10.9-16.6)$ & \\
\hline 5 or more days/week & $157(14.1)$ & 11 & $10.6(5.0-20.6)$ & & 43 & $16.3(11.9-22.1)$ & \\
\hline \multicolumn{8}{|l|}{ Global physical activity } \\
\hline$<300$ minutes / week & $871(80.0)$ & 76 & $76.5(67.5-83.6)$ & $0.84 *$ & 194 & $74.7(69.8-79.0)$ & $<0.01^{\mathrm{b} *}$ \\
\hline 300 minutes / week & $96(8.8)$ & 10 & $10.5(5.4-19.4)$ & & 37 & $14.3(6.7-28.1)$ & \\
\hline More than 300 minutes / week & $122(11.2)$ & 13 & $13.0(4.7-30.8)$ & & 28 & $11.0(5.6-20.2)$ & \\
\hline
\end{tabular}

$\mathrm{CI}=$ Confidence interval; $\mathrm{a}=$ Minimum wage of $\mathrm{R} \$ 724,00 ; \mathrm{b}=\mathrm{p} \leq 0.05 ; *=$ Chi-square test. $* *=$ Fisher's exact test.

The crude analysis of the relationship between abdominal obesity and the other variables showed that adolescents who performed two and three or more Physical Education classes per week were $45 \%$ and $71 \%$ less likely of having abdominal obesity, respectively. In the adjusted analysis, adolescents who actively commuted to school within 10 minutes or longer were $36 \%$ less likely of having abdominal obesity (Table 2). The final model of associations tested was composed of the variables commuting to school and physical activity during school recess, which presented an explanation capacity of $1.7 \%$ (pseudo $\mathrm{R}^{2}=$ 0.0172 ) in the WC variation. This model obtained values close to those of the saturated model and better than those of the null model, identifying that the variables inserted in that model were adjusted to each other and in relation to the outcome.

The crude analysis of the relationship between excess body weight investigated by means of BMI and the other variables showed that adolescents who actively commuted to school within 10 minutes or longer were $37 \%$ less likely of having excess body weight. In the adjusted analysis, this relationship remained statistically significant, and indicated that adolescents who actively commuted to school for less than 10 minutes or longer had a $25 \%$ less chance of having excess weight (Table 3 ). The final model of the associations tested was composed of the variables commuting to school and physical activity to improve endurance and muscular strength, which had an explanatory power of $3.4 \%$ (pseudo $\mathrm{R}^{2}=0.0338$ ) in body fat variation. The indicators used to verify the variables inserted in the final model indicated that the variables inserted in that model were adjusted to each other and in relation to the outcome. 
Table 2. Odds ratios and $95 \%$ confidence intervals in the association between abdominal obesity and independent variables in schoolchildren enrolled in public schools of São José, SC, Brazil, 2014.

\begin{tabular}{|c|c|c|c|c|c|c|}
\hline \multirow[t]{2}{*}{ Variable } & \multicolumn{3}{|c|}{ Crude analysis } & \multicolumn{3}{|c|}{ Adjusted analysis* } \\
\hline & OR & $(\mathrm{CI} 95 \%)$ & $\mathbf{p}$ & OR & $(\mathrm{CI} 95 \%)$ & $\mathbf{p}$ \\
\hline \multicolumn{7}{|l|}{ Commuting to school } \\
\hline Passive & 1 & & 0.10 & 1 & & $<0.05$ \\
\hline$<10$ minutes & 0.90 & $(0.41-1.94)$ & & 1.06 & $(0.63-1.78)$ & \\
\hline 10 minutes or more & 0.69 & $(0.44-1.09)$ & & 0.64 & $(0.58-0.71)$ & \\
\hline \multicolumn{7}{|l|}{ Number of Physical Education classes } \\
\hline No class per week & 1 & & $<0.01$ & 1 & & 0.79 \\
\hline One class per week & 0.47 & $(0.16-1.34)$ & & 0.71 & $(0.22-2.32)$ & \\
\hline Two classes per week & 0.55 & $(0.31-0.97)$ & & 0.88 & $(0.55-1.41)$ & \\
\hline Three or more classes per week & 0.29 & $(0.19-0.43)$ & & 0.66 & $(0.12-3.60)$ & \\
\hline \multicolumn{7}{|l|}{ Physical activity during school recess } \\
\hline Sedentary behavior (sitting) & 1 & & 0.13 & 1 & & 0.17 \\
\hline Physical activity (walking, running, actively playing) & 0.69 & $(0.37-1.29)$ & & 0.85 & $(0.61-1.18)$ & \\
\hline \multicolumn{7}{|l|}{ Physical activity to improve endurance and muscle strength } \\
\hline Does not perform & 1 & & 0.50 & 1 & & 0.72 \\
\hline 1 to 2 days/week & 0.97 & $(0.65-1.42)$ & & 1.32 & $(0.61-2.83)$ & \\
\hline 3 to 4 days/week & 1.41 & $(0.56-3.55)$ & & 2.09 & $(0.45-9.75)$ & \\
\hline 5 or more days/week & 0.67 & $(0.25-1.80)$ & & 0.84 & $(0.20-3.53)$ & \\
\hline \multicolumn{7}{|l|}{ Global physical activity } \\
\hline$<300$ minutes / week & 1 & & 0.43 & 1 & & 0.44 \\
\hline 300 minutes / week & 1.18 & $(0.65-2.13)$ & & 1.03 & $(0.50-2.09)$ & \\
\hline More than 300 minutes / week & 1.16 & $(0.50-2.69)$ & & 1.22 & $(0.42-3.53)$ & \\
\hline
\end{tabular}

OR - Odds Ratio; CI - Confidence interval; * - Analysis adjusted for gender, age, monthly family income, maternal schooling, sexual maturation and other independent variables, in which those who had $\mathrm{p} \leq 0.20$ were removed; The final model was formed by variables commuting to school Odds Ratio; CI - Confidence interval; * - Analysis adjusted for gender, age, monthly family income, maternal schooling, sexual maturation and other independent variables, in which those who had $\mathrm{p} \leq$ 0.20 were removed; The final model was formed by variables commuting to school.

Table 3. Odds ratios and 95\% confidence intervals in the association between excess weight and independent variables in schoolchildren enrolled in public high schools of São José, SC, Brazil, 2014.

\begin{tabular}{|c|c|c|c|c|c|c|}
\hline \multirow[t]{2}{*}{ Variable } & \multicolumn{3}{|c|}{ Crude analysis } & & \multicolumn{2}{|c|}{ Adjusted analysis* } \\
\hline & OR & $(\mathrm{CI} 95 \%)$ & $\mathbf{p}$ & OR & (CI95\%) & $\mathbf{p}$ \\
\hline \multicolumn{7}{|l|}{ Commuting to school } \\
\hline Passive & 1 & & 0.18 & 1 & & 0.01 \\
\hline$<10$ minutes & 0.96 & $(0.56-1.64)$ & & 0.99 & $(0.94-1.03)$ & \\
\hline 10 minutes or more & 0.63 & $(0.46-0.86)$ & & 0.75 & $(0.65-0.86)$ & \\
\hline \multicolumn{7}{|l|}{ Number of Physical Education classes } \\
\hline No class per week & 1 & & 0.78 & 1 & & 0.79 \\
\hline One class per week & 0.80 & $(0.26-2.42)$ & & 0.72 & $(0.21-2.46)$ & \\
\hline Two classes per week & 0.86 & $(0.41-1.82)$ & & 0.90 & $(0.41-1.97)$ & \\
\hline Three or more classes per week & 0.86 & $(0.22-3.30)$ & & 0.74 & $(0.22-2.51)$ & \\
\hline \multicolumn{7}{|l|}{ Physical activity during school recess } \\
\hline Sedentary behavior (sitting) & 1 & & 0.77 & 1 & & 0.26 \\
\hline Physical activity (walking, running, actively playing) & 1.04 & $(0.58-1.84)$ & & 1.23 & $(0.70-2.16)$ & \\
\hline \multicolumn{7}{|l|}{ Physical activity to improve endurance and muscle strength } \\
\hline Does not perform & 1 & & 0.18 & 1 & & 0.12 \\
\hline 1 to 2 days/week & 1.04 & $(0.33-3.26)$ & & 1.36 & $(0.45-4.15)$ & \\
\hline 3 to 4 days/week & 1.53 & $(0.83-2.83)$ & & 1.84 & $(0.82-4.13)$ & \\
\hline 5 or more days/week & 1.29 & $(0.67-2.52)$ & & 1.55 & $(0.65-3.70)$ & \\
\hline \multicolumn{7}{|l|}{ Global physical activity } \\
\hline$<300$ minutes / week & 1 & & 0.09 & 1 & & 0.40 \\
\hline 300 minutes / week & 2.19 & $(1.48-3.23)$ & & 1.87 & $(0.67-5.28)$ & \\
\hline More than 300 minutes / week & 1.01 & $(0.58-1.75)$ & & 0.82 & $(0.56-1.20)$ & \\
\hline
\end{tabular}

OR - Odds Ratio; CI - Confidence interval; * - Analysis adjusted for gender, age, monthly family income, maternal schooling, sexual maturation and other independent variables, in which those who had $\mathrm{p} \leq 0.20$ were removed; The final model was formed by variables commuting to school and physical activity to improve endurance and muscle strength presented pseudo $\mathrm{R}^{2}=0.0338 ; \mathrm{AIC}=807.67$ and $\mathrm{BIC}=843.80$. In comparison to the saturated model (pseudo $\mathrm{R}^{2}=$ 0.0389 , $\mathrm{AIC}=776.21$ and $\mathrm{BIC}=825.36$ ) and the null model (pseudo $\mathrm{R}^{2}=0, \mathrm{AIC}=1,165.40, \mathrm{BIC}=1,170.32$ ), the final model had value of 0.20 and $<0.001$, respectively, by the likelihood ratio test. 


\section{Discussion}

The main findings of this study were that adolescents who actively commuted to school ( $\geq 10$ minutes) had lower odds of developing abdominal obesity and were less likely of having excess weight when compared to adolescents who passively commuted to school. The other contexts of physical activity investigated were not associated with excess weight and abdominal obesity.

The results verified in the present study are in agreement with the findings in the research carried out with the participation of 789 North American adolescents aged 12-19 years, in which active commuting to school was inversely associated to BMI score; however, no association was observed with $\mathrm{WC}^{10}$. In another study involving 6,797 adolescents aged 9-11 from 12 countries, it was observed those who actively commuted to school had lower BMI values and lower odds of developing abdominal obesity ${ }^{5}$. A survey of 1,570 schoolchildren aged 7-12 years in the city of Joao Pessoa, Brazil, found that excess weight, measured by means of BMI, was higher among passive students ( $26 \%$ to $32 \%$ ) or those active for less than ten minutes $(25 \%)$, in relation to those who actively commuted to school for a time greater than or equal to 10 minutes $^{23}$.

A possible justification for the association between active commuting to school and abdominal obesity and excess weight can be explained by the fact that active commuting is associated with increased cardiorespiratory fitness and improved maximal oxygen uptake $\mathrm{e}^{24}$, and these organic adaptations result in greater energy expenditure and directly imply a negative energy balance ${ }^{7,25}$. Another aspect that could justify this interrelationship is the fact that habitual activities such as walking and cycling, as well as physical activities that demand moderate energy expenditure, stimulate the release of irisin, a hormone that transforms white adipose tissue associated with obesity into brown adipose tissue ${ }^{26}$. Brown adipose tissue cells have more mitochondria, resulting in higher caloric expenditure ${ }^{26}$.

In Brazil, the habit of traveling on foot or by bicycle is still little practiced ${ }^{27}$. This could be attributed to cultural aspects present in the Brazilian population, from which economically disadvantaged individuals move about on foot or by bicycle. In addition, the lack of appropriate structures for active displacement, such as the absence of cycling paths and pedestrianonly lanes, may contribute to low active displacement practice ${ }^{28}$. The other contexts investigated in the present study did not present a significant association with abdominal obesity and excess weight. Apossible explanation for the absence of the relationship between the performance of Physical Education classes and excess weight and abdominal obesity can be justified by the adolescents lack of interest in these classes, since the literature reports that older adolescents participate less in Physical Education classes compared to younger adolescents (up to 15 years of age $)^{29}$ and some are dismissed due to working hours. In addition, studies have indicated that many activities performed during Physical Education classes do not reach moderate to vigorous intensity, and therefore do not provide sufficient benefits for the improvement of body composition ${ }^{29}$.
School recess also had no significant association with abdominal obesity and excess weight. School organization may be a factor in the absence of this relationship ${ }^{30}$. The recess period is small and adolescents prioritize feeding, and there are few suitable spaces for the practice of physical activities ${ }^{30}$. In addition, adolescents do not want to show signs of tiredness, such as sweat, due to established beauty standards ${ }^{28}$.

In the present study, physical activities to improve muscular strength and endurance were not significantly associated with excess weight and abdominal obesity. Physical activities to improve muscular strength and endurance aim to strengthen muscles and, generally, are not performed with high intensity, and therefore may not increase enough energy expenditure to obtain benefits to reduce excess weight and abdominal obesity ${ }^{24}$. In addition, global physical activity was not associated with excess weight and abdominal obesity. Although physical activity as a strategy to reduce obesity is recommended, not having investigated the food consumption of these adolescents could justify the absence of significance for the association of these variables. Or, incipient causality in cross-sectional studies may also explain the absence of the relationship. In addition, the instrument used to measure global physical activity, the questionnaires, presents as a limitation the bias of recall and interpretation ${ }^{17}$. Although large-scale surveillance surveys use them because of their practicality, low cost, and because they do not affect the routine of the participants, they are ultimately subjetictive measures. The research design, which does not allow for inferring cause and effect, may also explain the absence of the association.

The main limitation of this study was the use of subjective measures to evaluate different patterns of physical activity. Although the scientific literature has objective instruments to measure physical activity, such as accelerometers, the cost of acquiring such equipment is high, which may hinder research with large samples. In addition, the absence of reference methods to measure abdominal fat is also a limitation of the present study. . The main strengths of this study are the different contexts of physical activity investigated, inside and outside the school environment. Another aspect considered a strong point of this research was the sample investigated, which is representative of the population of adolescent schoolchildren of a city in southern Brazil.

This research presents contributions to the health area, since it identified aspects related to excess weight and abdominal obesity, investigated through WC and BMI in adolescents. Possible actions and strategies that can encourage the practice of active commuting to and from school would beincreasing the awareness of parents and managers of schools; the creation of projects that allow practice of activities, such as cycling, racing and walking days; and the creation of new spaces, such as bike paths. Active commuting to school can present important contributions for adolescents in meeting physical activity recommendations, since it presents low financial cost. Active commuting can also promote physiological and social benefits and provide opportunities for adolescents to interact with the environment they live in, encouraging others to adopt a more active lifestyle. 


\section{Conclusion}

Active commuting to school was inversely associated with abdominal obesity and excess weight. Adolescents who had at least 10 minutes of active commuting to school were less likely of having abdominal obesity and excess body fat. Thus, actions should be implemented to increase the active commuting in adolescents, with the objective of obtaining benefits in the improvement of body composition.

\section{References}

1. Kelishadi R, Mirmoghtadaee P, Najafi H, Keikha M. Systematic review on the association of abdominal obesity in children and adolescents with cardio-metabolic risk factors. J Res Med Sci. 2015;20(3):294.

2. Moraes FGL, Oliveira LC, Araujo, TL, Matsudo V, Barreira, TV, Tudor-Locke C, Katzmarzyk, P. Moderate-to-vigorous physical activity and sedentary behavior: independent associations with body composition variables in Brazilian children. Pediatr Exer Sci. 2015;27(3):380-389.

3. Janssen I, Katzmarzyk PT, Srinivasan SR, Chen W, Malina RM, Bouchard C, Berenson GS. Combined influence of body mass index and waist circumference on coronary artery disease risk factors among children and adolescents. Pediatrics. 2005;115(6):1623-1630.

4. Janssen I, Leblanc A. Systematic Review of the Health Benefits of Physical Activity and Fitness in School-Aged Children and Youth. Int J Behav Nutr Phys Act. 2010;7:40.

5. Sarmiento OL, Lemoine P, Gonzalez SA, Broyles ST, Denstel KD, Larouche R, Hu G. Relationships between active school transport and adiposity indicators in school-age children from low-, middleand high-income countries. Int J Obes. 2015;5(1):107-114.

6. Van Dyck D, Cardon G, Deforche B, Sallis JF, Owen N, De Bourdeaudhuij I. Neighborhood SES and walkability are related to physical activity behavior in Belgian adults. Prev Med. 2010;50:74-9.

7. Larouche R, Saunders TJ, John Faulkner GE, Colley R, Tremblay M. Associations between active school transport and physical activity, body composition, and cardiovascular fitness: a systematic review of 68 studies. J Phys Act Health. 2014;11(1), 206-227.

8. Lubans DR, Boreham CA, Kelly P, Foster CR. The relationship between active travel to school and health-related fitness in children and adolescents: a systematic review. Int J Behav Nutr Phys Act. 2011;8:5.

9. Lopez JAH, Ochoa PY. Moderate to Vigorous Physical Activity during Recess and Physical Education by Gender and Body Fat. Med Sci Sports Exerc. 2015;49(5):980-988.

10. Martínez $\square$ Gómez D, Welk GJ, Puertollano MA, del $\square$ Campo J, Moya JM, Marcos A, Veiga OL. Associations of physical activity with muscular fitness in adolescents. Scand J Med Sci Sports. 2011;21(2):310-317.

11. World Health Organization. Obesity and overweight. Fact sheet No. 311. Updated January. World Health Organization: Gineve, Switzerland. 2015.
12. Silva DAS, Tremblay M, Pelegrini A, Silva RJds, de Oliveira ACC, Petroski EL. Association between aerobic fitness and high blood pressure in adolescents in Brazil: evidence for cruterionreferenced cut-points. Pediatr Exer Sci. 2016;28(2):312-20.

13. Taylor RW, Jones IE, Williams SM, Gouding A. Evaluation of waist circumference, waist-to-hip ratio, and the conicity index as screening tools for high trunk fat mass, as measured by dualenergy X-ray absorptiometry, in children aged 3-19 y. Am J Clin Nutr. 2000;72(2):490-5.

14. De Onis M, Onyango AW, Borghi E, Siyam A, Nishida C, Siekmann J. Development of a WHO growth reference for school-aged children and adolescents. Bull World Health Organ. 2007;85(9):660-7..

15. Oliveira ES, Nahas MV, Hoefelmann LP, Lopes AS. Associações entre atividade física, índice de massa corporal e comportamentos sedentários em adolescentes. Rev Bras Epidemiol. 2008:159-68.

16. Kowalski KC, Crocker PR, \& Faulkner, R. A. Validation of the physical activity questionnaire for older children. Pediatr Exer Sci. 1997;9(2):174-186.

17. Guedes DP, Guedes JERP. Medida da Atividade Física em Jovens Brasileiros: Reprodutibilidade e Validade do PAQ-C e do PAQ-A. Rev Bras Med Esporte. 2015;21(6):425-432.

18. Nahas M, Barros M, Florindo A, Farias Júnior J, Hallal P, Konrad L. Reliability and validity of the Saúde na Boa questionnaire to assess physical activity and eating habits of high-school students. Rev Bras Ativ Saúde. 2007;13:80-5.

19. Guedes DP, Lopes CC. Validação da versão brasileira do youth risk behavior survey 2007. Rev Saúde Públ. 2010;44(5)840-50.

20. IBGE. Metodologia do Censo Demográfico 2010. Rio de Janeiro: Instituto Brasileiro de Geografia e Estatística - IBGE; 2013.

21. Marshall WA, Tanner JM. Variations in pattern of pubertal changes in girls. Arch Dis Child. 1969;44(235):291-303.

22. Adami F, Vasconcelos FdAd. Obesidade e maturação sexual precoce em escolares de Florianópolis-SC. Rev Bras Epidemiol. 2008;11(4):549-60.

23. Silva KS, Lopes AS. Excesso de peso, pressão arterial e atividade física no deslocamento à escola. Arq Bras Cardiol. 2008;91(2):93-101.

24. Aires L, Pratt M, Lobelo F, Santos RM, Santos MP, Mota J. Associations of cardiorespiratory fitness in children and adolescents with physical activity, active commuting to school, and screen time. J Phys Act Health. 2011;8(2):198-S205.

25. Verhoeven H, Simons D, Van Cauwenberg J, Van Dyck D, Vandelanotte C, de Geus B, Deforche B. Promoting Active Transport in Older Adolescents Before They Obtain Their Driving Licence: A Matched Control Intervention Study. PloS One. 2016;(12).

26 Sippel CA, Bastian RMDA, Giovanella J, Faccin C, Contini V, Dal Bosco SM. Inflammatory processes of obesity. Rev Aten Saude. 2014; 12(42):48-56.

27. Corseuil MW, Schneider IJC, Silva DAS Costa FF, Silva KS, Borges LJ, d'Orsi E. Perception of environmental obstacles to commuting physical activity in Brazilian elderly. Prev Med. 2011;53(4):289-292.

28. Silva KS, da Silva Lopes A, da Silva FM. Atividade física no deslocamento à escola e no tempo livre em crianças e adolescentes 
da cidade de João Pessoa, PB, Brasil. Rev Bras Cienc Mov. 2008;15(3):63-70.

29. Sawyer SM, Afifi RA, Bearinger LH, Blakemore S-J, Dick B, Ezeh AC, Patton GC. Adolescence: a foundation for future health. Lancet. 2012379:1630-1640.

30. Kopp D, Prat I, Azevedo, M. Intervenções escolares de médio e longo prazo para promoção de atividade física: Revisão sistemática. Rev Bras Ativ Fis Saude. 2014;19(2):

\section{Corresponding author}

${ }^{*}$ Diego Augusto Santos Silva

Universidade Federal de Santa Catarina, Centro de Desportos, Departamento de Educação Física, Campus Universitário, Trindade, Florianópolis, Santa Catarina, Brasil.

Email: diegoaugustoss@yahoo.com.br

Manuscript received on July 17, 2017

Manuscript accepted on September 16, 2017

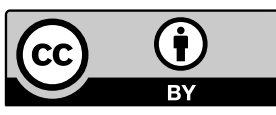

Motriz. The Journal of Physical Education. UNESP. Rio Claro, SP, Brazil - eISSN: 1980-6574 - under a license Creative Commons - Version 3.0 